\title{
1. Values and human rights: implications of an emerging discourse on virtue ethics
}

\author{
Michael L. Penn
}

\section{INTRODUCTION TO VIRTUE ETHICS AND HUMAN RIGHTS}

In the 1950s a group of philosophers at Oxford sought to construct a "virtue ethics" as a viable alternative to prevailing ethical systems. Virtue ethics, which draws much of its inspiration from the work of Aristotle, has since become the predominant moral theory and has focused attention on concepts that had long been neglected or insufficiently explained by the two other dominant ethical theories - deontology and utilitarianism. These neglected areas of moral philosophy included such themes as the concept of moral wisdom and the role of education in its cultivation and refinement; the nature of authentic friendship; the source or sources of true and enduring happiness; the appropriate role of emotions in human life and development; and most vitally, the central questions of what the virtues are and how we should best live if we wish to embody them.

What renders virtue ethics unique is that it concerns itself primarily with moral selves, as opposed to moral laws. This emphasis on the development and refinement of the self has greatly expanded the horizons of contemporary moral philosophy, and has contributed to a renewed search for both those universal values that best facilitate well-being and those indices of character development that are recognized around the world and across traditions as indicative of moral maturity. Inasmuch as the work of Amartya Sen and Martha Nussbaum has refocused the discourse in development on the cultivation of human capabilities as a way to advance human rights, here we explore how a capabilities approach might be enriched by the literature on virtue ethics. Such an exploration 
may be of special relevance in an age in which non-state actors, like corporations or everyday citizens, can pose as great a threat to human rights as the threat posed by tyrannical, rogue, or authoritarian governments.

\section{THE ROLE OF VIRTUE ETHICS IN HUMAN RIGHTS DISCOURSE}

One should begin by noting that discourse on virtues has largely been absent from modern human rights literature because virtues are generally thought to be private matters that animate the lives of individuals and are thus outside the scope of human rights theory and practice. Rather than focus on virtues, human rights theorists tend to speak of universal values. The universal values to which states commit themselves serve to adumbrate rights-related aspirations while also serving to define the limits and responsibilities of agents acting on behalf of the state. For example, states that do not respect the limits and responsibilities imposed by the Universal Declaration of Human Rights, or the Convention on the Rights of the Child, or the Geneva Convention, are said to have violated human rights norms. In serious cases of such violations, state actors may be charged with human rights abuses, war crimes, "crimes against humanity," or other serious offenses.

Because of the tendency of human rights theorists and advocates to focus on adherence to norms and laws, where discussions of ethics have found their way into contemporary human rights literature the ethical systems that have animated these discussions have tended to be centered in deontological or utilitarian perspectives. Whereas deontology emphasizes adherence to duty as the appropriate criterion for fixing and evaluating the ethics of human action, and utilitarianism proposes the greatest good for the greatest number as a standard against which to judge the moral worth of any act, law, or policy, virtue ethics is grounded in the conviction that the moral sphere encompasses all dimensions of human life, and that it is impossible to protect the body politic if the cultivation and refinement of human character is ignored or neglected. Indeed, hundreds of years before an elaborate discourse on human rights had been developed, this view was captured in its nascent form in ancient Chinese philosophy, ${ }^{1}$ as well as two of Aristotle's works, the Nicomachean Ethics and the Politics. In the Nicomachean Ethics Aristotle wrote: "the end of political science is the supreme good, and political science is concerned with nothing so much as with producing a certain character in the citizens or in other words with making them good, and capable of performing 
noble actions." "2 Indeed, in Aristotle's view, moral education is the primary purpose of the political community.

The relative absence of virtue ethics as a focus of concern in human rights literature is rendered conspicuous by the fact that many human rights abuses require the consent and participation of thousands, nay, in many cases, millions of "ordinary" citizens. ${ }^{3}$ This realization prompted Hannah Arendt to title her most provocative work The Banality of Evil. By "banality" Arendt did not mean to suggest that Adolf Eichmann's horrific deeds were in any way ordinary. Rather, she wished to suggest that when he committed the crimes associated with the Holocaust, Eichmann was himself a rather ordinary person whose motives did not appear to be animated by sociopathic tendencies or any well-thought-out ideology. To the contrary, his actions stemmed from rather petty concerns centered upon the desire to enjoy regular professional promotions and the wish to be obedient to authority. In other words, while Eichmann's human rights abuses reflected moral failings that were unremarkable in their origins, they were nonetheless monumental in their consequences. Stanley Milgram's research at Yale, undertaken in the wake of the trials at Nuremberg, Tokyo, and Jerusalem, revealed that many of us can be transformed into Eichmanns under the right social conditions. ${ }^{4}$

The danger here is that the tendency to limit the discourse on human rights to laws, conventions, declarations, and the behavior of state actors has left the masses of humanity on the sidelines in the effort to advance human rights. Yet we know that infringements of human rights are often committed by non-state actors whose motives may be tied to a variety of personal, corporate, and cultural interests. For example, while many of the rights of children are violated when they are conscripted into armed forces by governments and militia, many rights are also trampled upon when children are exploited as laborers by local markets, are sold into virtual slavery by their neighbors, are forced into prostitution by their families, and are made the objects of pornography by cottage industries that proliferate across the globe.

Furthermore, deeply entrenched patterns in many regions of the world permit a small elite to reap the benefits of modernity at the expense of the vast, impoverished majority. Such conditions have sharpened concern for human rights and pointed to the urgency of involving a greater share of the world's people in the dialogue on how human rights and human development might be advanced. Brazil and South Africa, for example, provide striking examples of countries that combine first-world affluence for the few with third-world poverty for the masses. Moreover, the hasty 
rush toward modernization by many corrupt and incompetent rulers in the developing world - usually at the behest of one of the Cold War superpowers - led to the abandonment of collectively held value systems and the destruction of traditional ways of livelihood. Rural populations tended to lose control of their land, which was in many cases converted to use for cash crops, thereby destroying food security and leaving millions at the mercy of self-absorbed elites and impersonal market forces. ${ }^{5}$

Thus, conspicuous and unrestrained affluence amidst extreme levels of deprivation, a rapidly deteriorating natural environment that will place special burdens on the poor, and the search for conditions of justice and equity that foster the health and security of individuals and societies have inspired renewed reflection on the relationship between ethics, development, and human rights. Increasing numbers of theorists and human rights workers have begun to suggest that it is unlikely that we will be able to achieve anything that looks like human prosperity within the narrowly focused paradigm that has animated human rights and development discourse over much of the previous century. ${ }^{6}$ Commenting on the moral underpinnings of many of the global challenges we face in his remarks to the Millennium World Peace Summit in May of 2000, Albert Lincoln offered the following observation:

Our world is undergoing rapid and far-reaching changes, drawing humanity ever closer together into what some have called a global village. Cultures and peoples that, for most of history, have lived in isolation from one another are now interacting face-to-face, on a daily basis. Sadly, however, social progress and the growth of wisdom and understanding have not kept pace with material advances ... Looking beyond immediate crises and conflicts, one of the gravest dangers facing mankind comes from a generation of children growing up in a moral vacuum. Our hearts go out to the child-soldiers of Africa, the child-prostitutes of Asia and the desperate scavengers of the world's countless slums and refugee camps, victims of a poverty which is both spiritual and material. But we must not forget the millions of young people growing up in societies whose traditional value systems lie in ruins ... And lest we oversimplify the causes or remedies, let us also call to mind the young products of permissive liberalism in the West, some of whom are as well-armed and violence prone as their age-mates in less prosperous lands. ${ }^{7}$

These concerns are echoed by a number of scholars in a comprehensive volume titled The Globalization of Ethics: Religious and Secular Perspectives. In the opening essay Will Kymlicka noted: "transnational debates about ethics are increasingly unavoidable, given the intensity of 
interaction among the world's cultures. As globalization increases, ethics must itself become globalized."

A pioneer in the search for more workable solutions to the complex problems we face is the Noble Laureate and economist Amartya Sen. Sen's work has done much to shift the dialogue on development and rights away from its traditional focus on Gross Domestic Product as the primary indicator of development and toward a concern for what might be required to create the conditions that would best contribute to the flourishing of human capabilities. ${ }^{9}$ Reflecting on this shift in focus, the United Nations Development Programme noted:

The first Human Development Report, in 1990, presented human development as a people-centered approach to development. The human development approach shifted the development discourse from pursuing material opulence to enhancing human well-being, from maximizing income to expanding capabilities, from optimizing growth to enlarging freedoms. It focused on the richness of human lives rather than on simply the richness of economies, and doing so changed the lens for viewing development results. ${ }^{10}$

Adding momentum to these new currents in the dialogue on development and rights is the emerging field of "positive psychology." 11 In their explication of the work, the Seligman Research Alliance at the University of Pennsylvania observed that

The new field of Positive Psychology ... is about character strengths, including the capacity for love and work, courage, compassion, resilience, hope, creativity, social skills, integrity, self-knowledge, impulse control, future-mindedness, and wisdom. At the level of community, it is about the civic virtues and the institutions that nurture better citizenship, such as responsibility, civility, parenting, work ethic, leadership, volunteerism, and tolerance. ${ }^{12}$

Such calls for a new "global ethic" thus represent an expansion of the reach of human rights discourse. ${ }^{13}$ One of the questions yet to be addressed is how concern for human development and human rights might attract inspiration and support from the generality of humankind. It is likely that the answer to such a question can be found in extending the reach and foci of education. 


\section{HUMAN RIGHTS EDUCATION AND THE DEVELOPMENT OF HUMAN POTENTIAL}

Haslip and Penn (2020) have suggested that the implementation of programs that promote moral development and civic engagement among children and youth is apt to be critical to achieving both the UN Sustainable Development goals as well as the movement to advance human rights. They note that while educational reform plans rarely focus on children's moral development, "a peaceful future depends upon the full character and intellectual development of each generation." They further note, "Only by teaching children how to live an altruistic life of service can the world's educational systems serve as the moral bridge between a potentially sustainable and ethical society, on the one hand, and the children and youth who are needed to create such a society on the other." ${ }^{14}$ They continue:

the movement for sustainable development, and the principles it embodies, can only be realized universally if educators at all levels focus intentionally on every child shifting to a consciousness of cooperation and collaboration worldwide. Such a shift ... would be reflected in a shift away from the competitive struggle for existence and toward a spirit of compassion and altruism that is global in its reach, [and] will require the development of a much more mature form of moral agency than is currently achieved during schooling today. Indeed, we suggest that the cultivation of moral agency among children be measured as an essential feedback mechanism for curriculum reform. Absent the focus on moral development, which elevates consciousness beyond selfishness, dishonesty, and expediency motivation, the clash between competing interests, identities, and ideologies within and among cultures and countries will continue to retard achievement of sustainable development outcomes and arrest achievement of the values that are embodied in the effort to protect human rights. In short, if succeeding generations are not focused on altruistic service to humanity as a whole, we will continue to entangle ourselves in environment destroying competition for material resources and destructive conflicts that embody gross violations of human rights. Our educational systems need urgently to inculcate both the desire and the capacity to mobilize the talents and capacities of the young toward promoting the collective prosperity of all humankind. ${ }^{15}$

If an "ethic of care" is to be joined with an "ethic of justice" in the pursuit of human rights, and if such an ethic is to become an integral part of the systematic process of development that we associate with schooling, we will need a theory of ethics that is both adequate and appropriate. Here we suggest that such an approach might be found in "virtue ethics." 
What, then, is virtue ethics; how might an approach that is animated by insights developed within this conceptual framework be of benefit to the effort to promote and protect human rights? Why might the philosophy and values that animate virtue ethics prove attractive to people of diverse backgrounds and traditions around the world? In addition, how might the emerging literature on the "ethics of care" further enrich a virtues-centered approach to advancing human rights? It is to these questions that we now turn.

\section{VIRTUE ETHICS, AN ETHICS OF CARE, AND HUMAN RIGHTS}

In contrast to the social constructionist perspective, which holds that all values are simply impositions of human will, in his important paper The Typology of Moral Ecology Svend Brinkmann conceptualizes the human domain "as a moral ecology; as a meaningful world with moral properties that present human beings with moral reasons for action." ${ }^{\prime 16} \mathrm{In}$ that paper Brinkmann advances the view that the topos of human life that is, the space wherein humans live out their days - is saturated with moral reasons for action and that the human community cannot attain its potential excellence (its arête) unless it acquires the capacity to respond appropriately to the moral imperatives of human existence.

For example, Brinkmann has argued that some human acts are acts of "brutality" and we must come to recognize brutality when it is present. To perceive brutality requires the cultivation of the capacity for compassion and concern. Without the development of such an inner eye, acts of brutality do not awaken in us the proper response.

Commensurate with such a view, virtue ethicists assume that the protection and advancement of human rights requires the coming-into-being of a range of virtues, or certain excellences of character, that are embodied in the everyday lives of people and that permit them to perceive the moral dimensions of life and to respond appropriately to their demands. Thus, one might say that at the heart of virtue ethics is a concern for the cultivation of moral discernment as well as the ability to embody in one's self certain qualities of character upon which the moral ecology depends. And while it may be true, as the Stoics argued, that "virtue is its own reward," from the perspective of society the telos and ultimate end of virtue is the flourishing of humanity. In this sense, virtue ethicists seek to pursue human rights by creating the kind of moral landscape that is inimical to human rights violations. 
Virtue ethics is thus more than a moral theory. It embodies a vision of human flourishing and concerns itself with what it might mean to achieve human prosperity in the fullest sense of that term. It invites reflection on every form of excellence and seeks to secure the good of humankind by encouraging the deliberate cultivation of those qualities of character, intellect, and behavior that make it possible for each of us to contribute, whether locally or globally, to the processes of civilization. Virtue ethicists have tended to suggest that the protection of deep human interests requires a kind of power that goes beyond the force of law. They tend to prescribe pursuit of those capacities that we recognize in ourselves and others when we say that so-and-so is genuinely good, honorable, and worthy of respect.

The notion of "internal goods" is thus fundamental to the discourse in virtue ethics. In contrast to "external goods," such as wealth, prestige, power, luxuries, and comforts, which can all be had by fraud or the luck of birth, internal goods - such as purity of heart, noble-mindedness, courage, compassion, and so forth - can only be experienced if we become manifestations of these goods. What is more, while external goods can often be sources of conflict, competition, violence, and war, internal goods tend to enrich the lives of those who pursue them while also enhancing the quality of life in the wider community wherein they are reflected.

In explication of the social embeddedness of virtues, Blaine Fowers has argued that "There is no virtue without concrete activity"; ${ }^{17}$ and thus, as Charles Taylor suggested, "they cannot be conceived as a set of individual actions, but are essentially modes of social relations, of mutual action." ${ }^{\prime 18}$ In further defense of the view that insists on the social, as opposed to the person-centered notion of virtues, Frank Richardson provides a range of examples of what virtues may look like in action:

the shrewd practice of democratic politics without cynicism or corruption; ... questioning someone's political or religious beliefs in a respectful manner; cultivating the kind of loyal friendship that goes beyond mutual enjoyment and benefits; ... discerning whether it is wiser courageously to speak up or wait to join the issue another time; inspiring students to want to learn; exercising leadership among colleagues or in an organization that brings out the best in people; ... winning someone's trust without flattery or deceit; learning to write well; setting firm limits on a child while causing a minimum of guilt or discouragement; forgiving someone in a wholehearted manner when at all possible; maximizing the honesty possible in social, political, or professional situations; learning to detect vanity or envy in oneself and dissolve or transform the emotions involved; gaining the ability to put people at ease in various 
life situations; discriminating when in the pursuit of justice 'the perfect may be the enemy of the good'; and so forth. ${ }^{19}$

\section{THE ETHICS OF CARE}

Of all virtues, few are as relevant to the protection of human dignity and human rights as is the inclination to care for the plight and well-being of others. The literature on the "ethics of care" has thus emerged as an important companion to virtue ethics in the discourse on human rights.

While the normative philosophy that animates the ethics of care owes its origins to Sara Ruddick, Carol Gilligan, and Nel Noddings, as Virginia Held noted in her influential volume The Ethics of Care: Personal, Political, and Global, "the ethics of care has moved far beyond its original formulation ... (and) has been developed as a moral theory relevant not only to the so-called private realms of family and friendship, but to medical practice, law, political life, the organization of society, war, and international relations. ${ }^{~}{ }^{20}$ Furthermore, as it is with virtue ethics, the philosophy that undergirds the ethics of care embodies the conviction that care is both an ethical value and a set of practices. ${ }^{21}$

The values that are central to the ethics of care arise out of a consciousness of human vulnerability and need. When we are in our infancy and childhood, for example, our survival depends on those who are charged with feeding, clothing, and nurturing us; when we move into school we need teachers to care for our developing minds; when we are ill we depend upon healers to aid in our recovery; and when we grow old we often require care as we pass through a final stage of heightened vulnerability and need. We thus cannot protect human dignity and human rights unless we develop an adequate response to the human need for care. Such a response will have to be revealed in the institutions that we design to serve human needs, as well as in the qualities of character that inspire and empower us to express our caring in action. At minimum, these qualities are apt to include compassion, some degree of humility, and generosity of spirit.

The qualities of character addressed in virtue ethics and the ethics of care, though seemingly inconsequential when viewed in the light of the dramatic nature of human rights abuses, are relevant here because human rights violations do not suddenly appear. They tend to have long periods of incubation and take root in social settings where subtle acts of inhumanity have become the norm and various forms of insensitivity, intolerance, and bigotry are nourished and unchecked. 
During the 2016 presidential campaign, for example, the American people saw the ugly face of prejudice increasingly nurtured and legitimized. As a consequence, over the course of a year or two subtle forms of bigotry became more blatant until these morphed into more pernicious forms of assault perpetrated against blacks praying in churches, Jews worshipping in synagogues, and sexual minorities dancing in clubs. We know that these assaults were not unrelated to the politics of divisiveness, as the FBI reported steady increases in the number and range of hate crimes as the campaign proceeded. Similarly, the people of Rwanda saw the Hutus engage in systematic processes of dehumanization leading for months up to the genocide that left 70 percent of the country's Tutsi population murdered by militia groups and neighbors wielding machetes; and, of course, the German people were marinated for years in various forms of hostility and disregard for Jews in preparation for the Holocaust that would be visited upon them beginning with the Kristallnacht of 1938.

By contrast, Steven Pinker has shown how even subtle processes that nurture a sense of humanity can have dramatic effects on large populations. In his widely read book The Better Angels of Our Nature: Why Violence Has Declined, Pinker introduces readers to the sociologist Norbert Elias (1897-1990), who was born in Germany but left the country in 1933 in order to escape the Holocaust.

Pinker describes how Elias's magnum opus, The Civilizing Process, published in 1939, chronicled the experience of everyday life in medieval Europe as a consequence of exposure to manuscripts of etiquette. The work revealed how animalistic and violent the Europeans had been in the Middle Ages with respect to their tendencies toward extreme forms of violence for relatively minor assaults to their reputation or status. The work also revealed that as social etiquette became part of common discourse, there was a dramatic, corresponding decline in the homicide rate among Europeans. In exploring this work, Pinker notes that while today we think of etiquette books as "sources of handy tips for avoiding embarrassing peccadilloes," they were once "serious guides to moral conduct, written by the leading thinkers of the day.",22

As Pinker explains, the etiquette books of the Middle Ages began to shape human sensibilities in significant ways as they provided simple prescriptions for living that served to civilize relationships among Europeans of all classes. Commenting on this, Pinker writes:

Elias's theory ... attributes the decline in European violence to a larger psychological change ... He proposes that over a span of several centuries, 
beginning in the 11th or 12th and maturing in the 17th and 18th, Europeans increasingly inhibited their impulses, anticipated the long-term consequences of their actions, and took other people's thoughts and feelings into consideration. A culture of honor - the readiness to take revenge - gave way to a culture of dignity - the readiness to control one's emotions. ${ }^{23}$

In other words, violence in Europe began to decline, in part, as a function of a conscious effort to advance what has long been described as the "humanizing" process.

A second trend that Pinker associates with dramatic decreases in violence is what he has called the "Humanitarian Revolution." The humanitarian revolution was associated with the European Enlightenment, whose ideas and ideals reduced humanity's appetite for state-sponsored violence and torture and opened human hearts so that "people began to sympathize with more of their fellow humans, and were no longer indif-

ferent to their suffering." 24 Commensurate with this view, in Inventing Human Rights: A History, the historian Lynn Hunt noted that as people began, for example, to read novels that captured the lives and experiences of everyday people, the sphere of human compassion began to widen and people began to "imagine" human equality. The penning of the Declaration of Independence in America in 1776 and the promulgation of the Universal Declaration of Human Rights in 1948 were, in Hunt's view, seminal moments during which broader aspirations for human freedom and dignity were couched in terms so noble and beautiful that these documents won for the human rights movement many new adherents. Thus, it was not just the penning of declarations that proved important to the human rights movement, but also the wooing of human hearts. Virtuous thoughts, virtuous acts, and virtuous aspirations are powerful forces that attract and transform the human heart.

\section{VIRTUE ETHICS AND HUMAN CAPABILITIES}

According to Aristotelian thought, if I wish to see the capacities of an acorn realized, I will have to satisfy its needs. For example, there will have to be a certain amount of soil above and below the acorn, I will have to provide it with sufficient amounts of light and water, and I will have to give it adequate time if I expect to see the capacities of the acorn develop into the capabilities of an oak tree. Similarly, from the human capabilities perspective, human needs may be thought of as a form of assistance that is required for the development of human capacities. Furthermore, in 
contrast to desires, which may be particular to each person, human needs are thought to be both universal and satiable. Justice is achieved when humanity's legitimate needs are satisfied. Human needs are thus the proper focus of human rights claims. ${ }^{25}$

In this regard, the "human capabilities approach," pioneered by Amartya Sen and Martha Nussbaum, asks: "What does a life worthy of human dignity require; what does such a life need?" In answer, Nussbaum identified a bare minimum of ten "Central Capabilities" that ought to be protected by the force of human rights law. These include:

1. Life: Being able to live a complete and satisfying life into old age. Not having life cut short or being made such that it hardly seems worth living.

2. Bodily Health: Living with good health, and not in a state where ill health seriously affects the quality of life. Having access to medical help as needed. To have good food and be able to exercise in ways that sustain health.

3. Bodily Integrity: Being able to go where you want to go. Being free from attack and abuse of any kind. Being able to satisfy healthy bodily needs.

4. Senses, Imagination, and Thought: Being able to use all of one's senses. Being free to imagine, think, and reason. Having the education that enables this to be done in a civilized, human way. Having access to cultural experiences, literature, art, and so on and being able to produce one's own expressive work. Having freedom of expression, including political and religious.

5. Emotion: Being able to become attached to other things and people outside of ourselves, loving and caring for them. Experiencing grief, longing, gratitude, and justified anger. Not being subject to fear and anxiety or blighted by trauma or neglect.

6. Practical Reason: Being able to consider and develop understanding of good and evil, and to think critically about the world and one's own place in it. Being able to live with one's conscience.

7. Affiliation: Being able to associate with others, living with them and acting for them. Showing concern for people in general and interacting with others. Having sympathy and compassion, acting to help people. Seeking justice and making things right. Protecting others and the rights of people, including freedom of speech and freedom from fear.

8. Other Species: Being able to live with the full range of creatures and plants that inhabit the world around us. To be able to enjoy nature and appreciate its beauty.

9. Play: Being able to laugh, play games, and generally have fun. Not having one's enjoyment and recreation criticized or prevented.

10. Control Over One's Environment: Being able to participate in political activities, making free choice, and joining with others to promote political views. Being able to own property and goods on the same basis that others do so. Being able to seek and accept work, and to be treated reasonably at work. Being free from unwarranted search and seizure. ${ }^{26}$ 
The central capabilities articulated by Nussbaum have expanded the vision of those who work to promote human development and human rights in significant ways. But this expanded vision touches only lightly on humankind's unique and profound capacity to engage the moral dimensions of life and to embody those sterling qualities of character that are sources of solidarity, happiness, and well-being wherever in the world they appear. We thus believe that human virtues deserve greater attention than they have received from those who seek to promote human dignity and human rights. We are not alone in thinking this.

\section{ETHICS AND THE WISDOM TRADITIONS}

Over the centuries and across a diversity of cultures the wisdom traditions have nurtured understanding of the important role that moral faculties play in protecting dignity and securing rights. And while it is true that ethical systems can also be quite harmful when they function as ideologies, fair-minded observers can no more fault these traditions for the harm that has been done in their names by demagogues than we can fault all scientists for the harm that has been visited upon humankind using the resources that science and technology have placed at our disposal.

In point of fact, one might say that over the ages and across civilizations two traditions of learning have enriched and protected human life. One tradition has made exceptional progress in the West and concerns itself with knowledge and mastery of the sciences, technologies, and industries that represent the harvesting of the forces of nature; the other tradition, which has been the great gift of the East, has concerned itself with knowledge, mastery, and refinement of the self. Where the wisdom traditions have been pursued with sincerity of purpose, purity of motive, and a desire to achieve moral and spiritual excellence, they have resulted in the development of human beings that are as worthy of admiration as the great men and women that have distinguished themselves in the sciences. Mother Teresa, Fred Rogers, Martin King, Thich Nhat Hanh, and St Francis of Assisi are among those whose names come easily to mind. But there are billions more, unknown to most of us, who have been nurtured by moral systems that are as philosophically rich as virtue ethics and have, through disciplined adherence to the teachings of these systems, gathered a harvest of beautiful qualities whose influence quite naturally protects dignity and secures rights. Reflecting on the intrinsic 
value of the qualities nurtured by these traditions, the 14th Dalai Lama wrote:

Compassion and love are not mere luxuries. As the source both of inner and external peace, they are fundamental to the continued survival of our species. On the one hand, they constitute non-violence in action. On the other, they are the source of all spiritual qualities of forgiveness, tolerance and all the virtues. Moreover, they are the very thing that gives meaning to our activities and makes them constructive. There is nothing amazing about being highly educated; there is nothing amazing about being rich. Only if the individual has a warm heart do these attributes become worthwhile. ${ }^{27}$

The Native American sage Black Elk spoke of his people's early encounter with a "sacred woman" who helped the Sioux distinguish between the foolish and the wise; between that which would harm the people and that which would confer upon them benefit and honor. It was, he said, in the manner of her coming that his people were to learn of these things; it was in the quality of her own being that the will of the people turned from a preoccupation with self to a concern for the common good: "she came, very beautiful and singing ... 'With visible breath I am walking. A voice I am sending as I walk. In a sacred manner I am walking. With visible tracks I am walking. In a sacred manner I walk." ${ }^{28}$ In this way are the Sioux informed of the sacred nature of life; in this way are they made aware of the interdependence of all living beings; in this way are their eyes opened to the great mysteries that are enshrined within each rock and tree and bird upon the earth. To keep this knowledge alive and preserved from generation to generation, and to nurture the pure hearts and noble intentions upon which life depends, they taught themselves to pray:

Grandfather, Great Spirit ... lean close to the earth that you may hear the voice I send ... Give me the strength to walk the soft earth, a relative to all that is! Give me the eyes to see and the strength to understand, that I may be like you. With your power only can I face the winds ... Great Spirit, Great Spirit, my Grandfather, all over the earth the faces of living things are all alike. With tenderness have these come up out of the ground. Look upon these faces of children without number and with children in their arms, that they may face the winds and walk the good road to the day of quiet. This is my prayer; hear me! The voice I have sent is weak, yet with earnestness I have sent it. Hear me! ${ }^{29}$

In the Far East, Hsün Tzu spoke of the "rectification of names." By this is meant many things, but at its heart the rectification of names is concerned with the moral responsibility that we bear to ensure that our words 
are linked to truth and reality. When the sentiments of the heart and the words we speak are in harmony we escape the quagmire of hypocrisy. Such is Hsün Tzu's call to virtue.

In "Honoring the Worthy," the venerable Chinese philosopher Mo Tzu observed that "rulers and high officials who govern the nation all desire their states to be rich ... and their administration well ordered." And yet, "what they have achieved is not wealth but poverty ... not order, but chaos." Mo Tzu then asks, "Why is this?" He responds to his own question by noting that "rulers and high officials who govern the nation fail to honor the worthy." Nay, rather, they call to service men of low aim, of weak character - those whose spirits are charmed and attracted most powerfully by rank and wealth and status. What means, he continues, may be deployed in order to increase the number of truly worthy men? He responds:

Let us suppose that one wishes to increase the number of skilled archers and chariot drivers in the state. One must set about enriching and honoring such men, respecting and praising them. Once this has been done, one will have no difficulty in obtaining a multitude of them. How much more appropriate, therefore, that one should do this for worthy men, who are ardent in the practice of virtue, skilled in discourse, and broad in learning! Men such as these are the treasures of the nation ... They too should be enriched and honored, respected and praised. ${ }^{30}$

In this way does Mo Tzu affirm the ancient truth that civilization is carried forward on the backs of those whose minds and spirits are animated by good and praiseworthy qualities.

Similarly, the Buddhist sage Thich Nhat Hanh spoke of fourteen precepts, which, when observed, empower humanity to flourish:

1. Do not be idolatrous about or bound to any doctrine, theory, or ideology. All systems of thought are guiding means; they are not absolute truth.

2. Do not think that the knowledge you presently possess is changeless, absolute truth. Avoid being narrow-minded and bound to present views. Learn and practice non-attachment from views in order to be open to receive others' viewpoints. Truth is found in life and not merely in conceptual knowledge. Be ready to learn throughout your entire life and to observe reality in yourself and in the world at all times.

3. Do not force others, including children, by any means whatsoever, to adopt your views, whether by authority, threat, money, propaganda, or even education. However, through compassionate dialogue, help others renounce fanaticism and narrowness. 
4. Do not avoid contact with suffering or close your eyes before suffering. Do not lose awareness of the existence of suffering in the life of the world. Find ways to be with those who are suffering, by all means, including personal contact and visits, images, and sound. By such means, awaken yourself and others to the reality of suffering in the world.

5. Do not accumulate wealth while millions are hungry. Do not take as the aim of your life fame, profit, wealth, or sensual pleasure. Live simply and share time, energy, and material resources with those who are in need.

6. Do not maintain anger or hatred. Learn to penetrate and transform them while they are still seeds in your consciousness. As soon as anger or hatred arises, turn your attention to your breathing in order to see and understand the nature of your anger or hatred and the nature of the persons who have caused your anger or hatred.

7. Do not lose yourself in dispersion and in your surroundings. Practice mindful breathing in order to come back to what is happening in the present moment. Be in touch with what is wondrous, refreshing, and healing, both inside and around yourself. Plant the seeds of joy, peace, and understanding in yourself in order to facilitate the work of transformation in the depths of your consciousness.

8. Do not utter words that can create discord and cause the community to break. Make every effort to reconcile and resolve all conflicts, however small.

9. Do not say untruthful things for the sake of personal interest or to impress people. Do not utter words that cause division and hatred. Do not spread news that you do not know to be certain. Do not criticize or condemn things that you are not sure of. Always speak truthfully and constructively. Have the courage to speak about situations of injustice, even when doing so may threaten your own safety.

10. Do not use the religious community for personal gain or profit, or transform your community into a political party. A religious community should, however, take a clear stand against oppression and injustice, and should strive to change the situation without engaging in partisan conflicts.

11. Do not live with a vocation that is harmful to humans and nature. Do not invest in companies that deprive others of their chance to live. Select a vocation that helps realize your ideal of compassion.

12. Do not kill. Do not let others kill. Find whatever means possible to protect life and prevent war.

13. Possess nothing that should belong to others. Respect the property of others but prevent others from enriching themselves from human suffering or the suffering of other beings.

14. Do not mistreat your body. Learn to handle it with respect. Do not look on your body as only an instrument. Preserve vital energies for the realization of the Way. Sexual expression should not happen without love and commitment. In sexual relationships, be aware of future suffering that may be caused. To preserve the happiness of others, respect the rights and commitments of others. Be fully aware of the responsibility of bringing new 
lives into the world. Meditate on the world into which you are bringing new beings. ${ }^{31}$

Referencing African-centered systems of thought, Parham, Ajamu, and White note that at the core of African-centered psychology are four fundamental principles. ${ }^{32}$ The first is that spirit permeates everything that exists in the universe; the second is the notion that everything in the universe is interconnected; the third is that the value of the collective transcends and encompasses the value of the individual; and the fourth is that self-knowledge is the key to humanity's mental and social health. ${ }^{33}$ The human spirit is said to be cultivated when it is brought into harmony with a code of conduct that reflects these truths. Without these qualities of character, there could be no community; and without community, there could be no individual: "I am because we are; we are because I am."

We invoke these traditions because they reflect many of the same insights and values that are integral to virtue ethics. What is more, many of these ethical systems continue to inspire millions of people around the world. ${ }^{35}$ They thus represent cultural resources that can be more effectively mobilized in the service of development, dignity, and rights. But the people of the world must be invited to see themselves as protagonists in the processes of civilization building. They must be encouraged to develop and exercise the virtues that many respect and revere. We must create venues that empower the people of diverse ages, cultures, and backgrounds to express their deep longing for human solidarity and the well-being of their fellow creatures. We close with a few examples of such initiatives around the world.

\section{EXAMPLES OF VIRTUE ETHICS AT WORK}

\section{High Resolves}

High Resolves recently won the Aspen Institute's most prestigious prize for community service. It was created by Merdad and Roya Baghai 13 years ago. Today it uses high-impact experiences to inoculate students against hatred and empowers them to be of service to their communities. Since its founding the program has engaged over 200,000 young people in Australia alone. Its vision is to reach 50 percent of all Australian high schoolers in the next five years. In addition, it has expanded to hubs in Oakland, New Orleans, Canada, China, and Brazil, and has attracted the engagement of the UN Leaders Programme centered in Turin, Italy. In 
describing their work, Mehrdad and Roya write: "Being a good citizen is not intuitive ... Moral education is what is required to 'immunize' us against the blind prejudice that feeds human unkindness, and leads to human atrocities." ${ }^{\prime 36}$

\section{ServiceSpace}

The motto at ServiceSpace is "change yourself, change the world." The project is an experiment in the joy of giving that began 12 years ago and has grown into a worldwide movement. A sea of volunteers have developed an ecosystem of generosity-driven projects that touch the lives of thousands. In children, youth, and adults on every continent, it encourages the cultivation and practice of selflessness and compassion. Each project seeks to open up spaces so that everyone who desires to taste the sweetness of service in their own lives will find support in achieving this. It nurtures appreciation for beauty in the environment, beauty in one's approach to others, and beauty in one's inner life. One of its founders, Nipun Mehta, spoke of the values that are at the heart of this important work at the University of Pennsylvania's Commencement in 2012. ${ }^{37}$ His is one of the most widely viewed commencement addresses ever delivered, perhaps because it summons the graduates of this prestigious institution to a renewed commitment to the noblest aspirations of the human heart and to those qualities of character that we have in mind when we cannot help but admire others.

\section{John Templeton Foundation}

The John Templeton Foundation places millions of dollars every year at the disposal of scholars who are seeking to advance human well-being by undertaking research on the "big questions" of life and by promoting the development of character. Its desire is to promote "spiritual progress" by harvesting the power of science in order to advance our understanding of the most perplexing and challenging questions facing humanity. Many of these challenges fall within the sphere of ethics. Commenting on its ethics-related vision, the Templeton Foundation notes that it seeks to advance the science and practice of character, with a focus on moral performance and civic and intellectual virtues - such as humility, gratitude, curiosity, diligence, and honesty. Its current focus is to support initiatives 
that promote intellectual humility and the science of virtue. Six of the projects funded by Templeton that are currently underway include:

1. The Children's Hospital of Philadelphia Center to Promote Adolescent Health, Character, and Well-Being: A Research, Translation and Dissemination Initiative;

2. The Development of Forgiveness Project at the University of Virginia;

3. Nudging Empathy: Harnessing Motivation to Create Sustainable Empathetic Choices at Penn State University;

4. \#CultivatingCharacter: A Global Movement to Cultivate Character Both Online and Off Through Living 24/6 carried forward by Let it Ripple;

5. A Scientific Approach to Living in Love: A Framework for the Future at the University of North Carolina at Chapel Hill; and

6. The Virtues of Curiosity: How Eagerness to Learn Fosters Learning, Creativity and Engagement at Columbia University.

These are but three of the thousands of projects that are blossoming all over the world. Projects such as these hold much promise for bringing human virtues to life.

\section{NOTES}

1. See: Watson, B., Tzu, M., Tzu, H., Tzu, H.F., and Tzu, H. (1968). Basic Writings of Mo Tzu, Hsün Tzu, Han Fei Tzu. Journal of the American Oriental Society, 88(2), p. 367.

2. Aristotle (1987). The Nicomachean Ethics. Amherst, NY: Prometheus Books, p. 30.

3. For example, the Armenian genocide, the German genocide of the Jewish people, the Cambodian genocide, the Indonesian genocide, the Rwandan genocide, the Serbian genocide, and the genocides in Bangladesh, Darfur, Somalia, and Bosnia, as well as the Rohingya genocide (which is currently ongoing), all required the duplicity, and sometimes the active participation, of large numbers of otherwise ordinary people.

4. See: Blass, T. (2000). Obedience to Authority: Current Perspectives on the Milgram Paradigm. Mahwah, NJ: Lawrence Erlbaum Associates.

5. Bales, K. (2012). Disposable People: New Slavery in the Global Economy. Berkeley, CA: University of California Press, pp. 12-14.

6. See: Mustakova-Possardt, E., Lyubansky, M., Basseches, M., and Oxenberg, J. (eds) (2014). Toward a Socially Responsible Psychology for a Global Era. New York, NY: Springer.

7. The Millennium World Peace Summit: A Bahá'í Perspective, presented by Dr. Albert Lincoln to the United Nations General Assembly, 29 August 2000. www.bic.org/statements/millennium-world-peace-summit-bahai-perspective. 
8. Sullivan, M.W., and Kymlicka, W. (2008). The Globalization of Ethics: Religious and Secular Perspectives. Cambridge: Cambridge University Press, p. 1 of the Introduction.

9. See, for example: Sen, A. (2013). Development as Freedom. Oxford: Oxford University Press.

10. United Nations Development Programme (2016). Human Development Report 2016: Human Development for Everyone. New York: UNDP.

11. See: Lopez, S.J., and Snyder, C.R. (2011). Oxford Handbook of Positive Psychology. New York: Oxford University Press; Aspinwall, L., and Staudinger, U.M. (2003). A Psychology of Human Strengths: Fundamental Questions and Future Directions for a Positive Psychology. Washington, DC: American Psychological Association Press.

12. See: www.positivepsychology.org/mission.htm.

13. See also: Kung, H. (2020). Walls to Bridges: The Global Ethic. Mesa, AZ: iPub Global Connection.

14. Haslip, M., and Penn, M. (2020). Cultivating Human Rights by Nurturing Altruism and a Life of Service: Integrating UN Sustainable Development Goals into School Curricula. In H. Mahmoudi and M. Penn (eds) (2019). Interdisciplinary Perspectives on Human Dignity and Human Rights, pp. 151-73. Bingley: Emerald Publishing.

15. Ibid., p. 152.

16. Brinkmann, S. (2004). The Typology of Moral Ecology. Theory and Psychology, 14(1): 57-80, p. 59.

17. Fowers, B. (2005). Virtue Ethics and Psychology: Pursuing Excellence in Ordinary Practices. Washington, DC: American Psychological Association Press, p. 67.

18. Taylor, C. (1985). Interpretation and the Sciences of Man. In Philosophy and the Human Sciences: Philosophical Papers, Volume 2. Cambridge: Cambridge University Press, p. 36.

19. Richardson, F. (2011). On Psychology and Virtue Ethics. Journal of Theoretical and Philosophical Psychology, 32(1), 24-34.

20. Held, V. (2005). The Ethics of Care: Personal, Political, and Global. New York, NY: Oxford, p. 9.

21. Ibid.

22. Pinker, S. (2012). The Better Angels of our Nature: Why Violence has Declined. New York, NY: Penguin, p. 69.

23. Ibid., p. 72.

24. Ibid., p. 133.

25. For a discussion of these themes, see: Penn, M.L., and Malik, A. (2010). The Protection and Development of the Human Spirit: An Expanded Focus for Human Rights Discourse. Human Rights Quarterly, 32(3): 665-88.

26. For explication of these central capabilities, see, for example: Nussbaum, M.C. (2013). Creating Capabilities: The Human Development Approach. Cambridge, MA: Belknap Press.

27. Dalai Lama (2001). Ancient Wisdom, Modern World: Ethics for the New Millennium. New York, NY: Time Warner. 
28. Neihardt, J. (2008). Black Elk Speaks: Being the Life Story of a Holy Man of the Oglala Sioux. Albany, NY: State University of New York Press.

29. Ibid.

30. Mo Tzu, Honoring the Worthy. From Basic Writings of Mo Tzu, Hsün Tzu, and Han Fei Tzu, translated by Burton Watson. New York, NY: Columbia, pp. 19-20.

31. Kotler, A. (ed) (2004). The Thich Nhat Hanh Collection. New York, NY: One Spirit, pp. 127-9.

32. Parham, T., Ajamu, A., and White, J.L. (2016). The Psychology of Blacks: Centering Our Perspectives in the African Consciousness. Boston, MA: Pearson, pp. 4-5.

33. Ibid.

34. Press, B. (2011). I Am Because We Are: African Wisdom in Image and Proverb. St Paul, MN: Betty Press.

35. For a fuller discussion of this theme, see: Sullivan and Kymlicka (2008).

36. McNulty Foundation (n.d.). As Intolerance and Extremism Increase, High Resolves Teaches High Schoolers to Rise Above. https://mcnultyfound.org/ impact/stories/high-resolves.

37. See https://almanac.upenn.edu/archive/volumes/v58/n34/bacc-mehta.html. 